\title{
Studying on the Impact of Perceived Overqualification on Work Engagement: The Moderating Role of Future Work Self Salience and Mediating Role of Thriving at Work
}

\author{
Tianchen Lou, Maolin Ye* \\ Management School, Jinan University, Guangzhou, China \\ Email: *maolinye@163.com
}

How to cite this paper: Lou, T.C. and Ye, M.L. (2019) Studying on the Impact of Perceived Overqualification on Work Engagement: The Moderating Role of Future Work Self Salience and Mediating Role of Thriving at Work. Open Journal of Social Sciences, 7, 24-36.

https://doi.org/10.4236/jss.2019.78002

Received: July 9, 2019

Accepted: August 4, 2019

Published: August 7, 2019

Copyright $\odot 2019$ by author(s) and Scientific Research Publishing Inc. This work is licensed under the Creative Commons Attribution International License (CC BY 4.0).

http://creativecommons.org/licenses/by/4.0/

\begin{abstract}
The study was based on 205 valid questionnaires and we used a series of regression analysis to examine the effect of perceived overqualification (POQ) on work engagement (WE) and the associated underlying mechanism. The results show that: 1) POQ was negatively related to WE; 2) The relationship between POQ and WE was partially mediated by Thriving at work (WT); 3) Future work self salience (FWSS) moderated the relationship between POQ and WT, such that this relationship was not significant when FWSS was high.
\end{abstract}

\section{Keywords}

Perceived Overqualification, Work Engagement, Thriving at Work, Future Work Self Salience

\section{Introduction}

More than 80 percent of Chinese feel they have "no place for heroes," according to a global poll by the Canadian company Destad. In recent years, the average level of education for new employees has grown, but most basic jobs do not need to be that high [1]. This phenomenon, in which individuals' education, skill level and work experience exceed the requirements of actual work, is defined by academia as overqualification [1] [2]. There are subjective and objective points of overqualification [3]. And "perceived overqualification" refers to employees' perception of overqualification, which is a determinant of work results [4]. Therefore, this paper focuses on perceived overqualification. Previous studies are mostly based on the relative deprivation theory or equity theory, and believe that 
perceived overqualification will lead to low job satisfaction, low sense of organizational commitment, high turnover intention, and counterproductive workbehavior [1] [2] [5]. There are still plenty of theoretical perspectives and outcome variables in this study. Therefore, this study based on Self-determination theory (SDT) and starting from the internal perspective of individuals, explores the effect and mechanism of perceived overqualification on work engagement, and provides a new idea for enterprises to improve employees' work engagement from the perspective of motivation.

Work engagement refers to a state of active work characterized by "Vigor", "Dedication", and "Absorption", in which "Vigor" means being energetic and adaptable at work. "Dedication" means being actively involved and experiencing meaning, passion, motivation, pride and challenge. "Absorption" means that you are pleasantly absorbed in your work and it is difficult to separate yourself from it [6]. Since Kahn (1990) first put forward this concept, it has been paid much attention to in psychology, management and other fields [7]. Work engagement can effectively predict employees' job performance [7], so it is of great significance to explore work engagement's antecendent variable.SDT shows that people have three basic psychological needs, which are the necessary conditions for improving autonomous motivation and generating internal motivation [8], while individuals with perceived overqualification lack these three basic psychological needs and have low internal motivation, so perceived overqualification may affect work engagement.

Thriving at work refers to a continuous psychological state in which individuals experience "Litality" and "Learning" at the same time in their work. Vitality means that employees are enthusiastic and active, willing to work hard; Learning refers to the continuous learning of working skills and methods to adapt to the changing requirements of work [9]. It has been found that it positively affects job performance, organizational citizenship behavior, organizational loyalty and job satisfaction [10] [11]. SDT shows that the satisfaction of basic psychological needs can promote individual prosperity and development [12]. Due to the lack of basic psychological needs, employees with high perceived overqualification have a low status of thriving at work, which further affects their work engagement. Therefore, it is speculated that thriving at work is the mediating factor that perceived overqualification affects the work input.

Most previous studies have explored the moderating effect model of overqualification on employees' work results from the perspective of organizational context [13]. Therefore, based on SDT, this study introduced "future work self salience" as a moderating variable from the perspective of individual differences. "Future work self salience" refers to the degree of clarity and ease of imagination of an individual's future work self. It provides an individual with a different image from what he wants to be at present. Such difference can make him focus on change. Relevant studies show that future work self salience can positively affect active occupational behavior and career adaptability [14] [15]. This representation of self-image can make up for the lack of basic psychological needs of indi- 
viduals, improve internal motivation, and thus improve thriving at work of employees with perceived overqualification. This study will further explore the effect of future work self salience on the relationship between perceived overqualification and thriving at work.

In conclusion, a moderated mediation model is proposed, as shown in Figure 1.

\section{Theory and Hypotheses}

\subsection{POQ and Work Engagement}

SDT shows that people have three basic psychological needs - the needs for autonomy (feeling that actions are self-determined), competence (feeling influential in the interaction with the environment) and relatedness (feeling the support of others and social relationships) [8] [16], which is a necessary condition to improve autonomous motivation and internal motivation. In addition, the three basic psychological needs are affected by the environment [17] [18]. SDT divides the influence factors of external context into three types: informational, controlling and demotivational. Among them, the controlling envents reduces the internal motivation by influencing the individual's autonomy, and the demotivational environment reduces the internal motivation by influencing the individual's competence [12].

Individuals with high POQ believe that they are in a dismotivated environment and most of the work they do is not challenging [19], Individuals are unable to effectively influence the environment, unable to display their excessive qualification and improve their confidence by completing challenging tasks, and lack of competent needs; They also think they are restricted by rules or orders in a controlled environment, and lack autonomy in choosing the content of their work [20], and lack of autonomous needs; After the completion of the work, they can't get the correct evaluation and support from their superiors or colleagues, so they can't maintain meaningful contact with others, and lack of related needs [21]. As a peripheral factor, the related needs are also an important condition for the development of intrinsic motivation [8]. To sum up, individuals with high POQ have different degrees of lack of three basic psychological needs, and low internal motivation. SDT believes that there is a positive correlation between the satisfaction of individual basic psychological needs and work engagement [22], which is also an external manifestation of internal motivation [23] [24]. Therefore, individuals with a higher POQ may have lower work engagement.

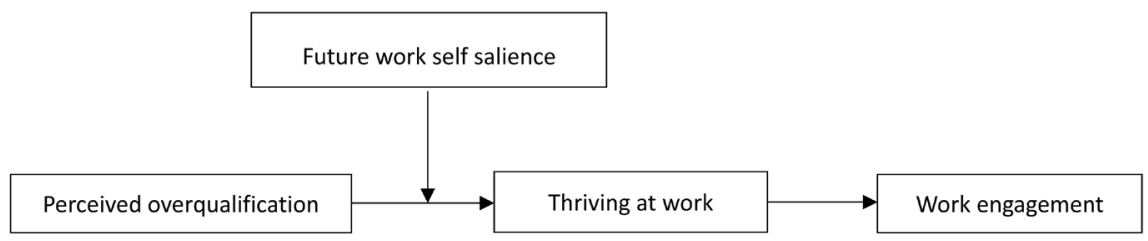

Figure 1. Theoretical model. 
In conclusion, the following hypothesis is proposed:

H1: POQ was negatively related to work engagement.

\subsection{The Mediation Role of Work Engagement}

SDT points out that the satisfaction of basic psychological needs can promote individual prosperity and development [12]. Individuals want to strive for the sense of autonomy, sense of competence and the sense of closeness with others to pursue prosperity and growth [16]. In addition, Spreitzer and Porath (2013) took SDT as the core and proposed an Integrative Model of Human Growth at Work, revealing how situational factors affect thriving at work and its results by affecting basic psychological needs [25]. Situational factors that affect basic psychological needs include feedback, decision-making discretion, climate of trust/respect, and broad information sharing etc. In the interaction with the working environment, individuals with a high POQ believe that their qualifications exceed the work requirements, and they cannot control their work autonomously, cannot get reasonable feedback, cannot make independent decisions and share information, so the needs for competence and autonomy are lacking [19] [20]. Without the approval and support of others, the atmosphere of trust and respect cannot be perceived, and the needs for relatedness will be correspondingly lacking. According to the model, individuals with high POQ cannot achieve "vitality" and "learning" at the same time, and thriving at work is low [25].

Relevant studies show that individuals with high level of thriving at work maintain energetic and enthusiastic attitude towards work, and stimulate individual's work self-efficacy and enthusiasm [10] [25], such enthusiastic and positive attitude and self-efficacy can promote individual's work engagement [26] [27]. In addition, when the individual works to a higher degree of prosperity, vitality and learning level is higher, it indicates that the three basic psychological needs of the individual are not lacking, and the individual internal motivation is stronger, which will also promote the work engagement [8] [16] [18].

Therefore, the individuals with high POQ have a lower state of thriving at work and less work engagement. And the individual with low POQ, thriving at work is higher, work engagement is higher. Based on this, the hypothesis is put forward:

H2: the relationship between POQ and work engagement was mediated by Thriving at work.

\subsection{The Moderation Role of Future Work Self Salience}

SDT also shows the influence of individual differences on motivation. It is believed that there are three orientations for people to produce and manage their own behaviors-autonomous, controlled and impersonal orientations. The combination of these three orientations to different degrees leads to individual differences, in which individuals with autonomous orientations will choose actions towards the goals set by themselves to achieve self-realization, self-development and 
interpersonal satisfaction [18]. Therefore, this study introduces future work self salience as an individual difference into the moderation model. Future work self salience refers to the degree to which individuals can clearly and easily imagine their future work and life, which will motivate them and enhance their internal motivation [15] [28].

For high POQ of individual, when its future work self salience is high, production and management of behavior are more likely to be based on autonomous orientation, individual is eager to have a positive identity or role in the work [29], and through the cognitive framework based on the future [30], to set own goals, to achieve self-realization, so it can meet the needs for autonomy, improve the work autonomy and keep the vitality and enthusiasm in work [18]. And setting challenging goals for career [31]. By promoting work roles, self-efficacy and goal commitment can be enhanced to meet the needs for competency [26], which is conducive to further acquisition and utilization of knowledge and skills and building up high confidence. And want to develop good relationships to meet the needs for relatedness and to promote thriving at work.

Therefore, when future work self salience is high, the basic psychological needs of individual can be satisfied, and the negative impact of POQ on thriving at work can be alleviated. However, when future work self salience is low, the basic psychological needs of individuals with high POQ are not satisfied, and thriving at work cannot be promoted.

In conclusion, further hypothesis is proposed:

H3: Future work self salience plays a negative moderating role between POQ and thriving at work. The level of future work self salience is higher, the more it alleviates the negative influence of POQ on thriving at work.

H4: Future work self salience moderates the indirect effect of POQ on work engagement through thriving at work, such that the indirect effect is more negative when the level of future work self salience is higher than when it is low.

\section{Sample and Measures}

The subjects are from MBA class of three universities and employees of enterprises in Guangzhou introduced by acquaintances. In order to avoid homologous variation, data were collected at two time points by questionnaire survey, and through the end of the phone number and the first letter of the name to match. Firstly, data on demographic information, perceived overqualification and future work self salience were collected (Time 1), a total of 289 questionnaires were distributed, after deleting invalid questionnaires, 256 of which were valid. One month later (Time 2), data collection on thriving at work and work engagement was carried out, A total of 256 questionnaires were distributed, after deleting invalid questionnaires, 223 of which were valid, 205 questionnaires were finally retained after deleting the questionnaires that were difficult to match with Time 1.

In order to obtain the scale suitable for this study, all scales were translated from English to Chinese and back-translated, and has been compiled by domes- 
tic scholars and has been verified to be of good reliability and validity in previous studies.

POQ: The perceived overqualification scale developed by Fine and Nevo (2008), with likert 5-point scoring, a total of 9 items in two dimensions, including two reverse scoring items. The dimension of cognitive mismatch contains 4 items, and the dimension of cognitive non-growth contains 5 items [32]. The cronbach's alpha coefficient was of the scale in the study was 0.81 .

Thriving at work: The thriving at work scale developed by Porath et al. (2012), with likert 7-point scoring, has 10 items in two dimensions, including two reverse scoring items. The vitality dimension and learning dimension each contain 5 items [10]. The cronbach's alpha coefficient was of the scale in the study was 0.89 .

Work engagement: The short version of work engagement scale developed by Schaufeli et al. (2006), with likert 7-point scoring, has 9 items in three dimensions, including 3 items in vigor dimension, 3 items in dedication dimension and 3 items in absorption dimension [6]. The cronbach's alpha coefficient was of the scale in the study was 0.95 .

Future work self salience: The single dimension scale of future work self salience developed by Strauss et al. (2011), with 5 items in total [15]. The cronbach's alpha coefficient was of the scale in the study was 0.93 .

According to previous studies, gender, age, position, tenure and years of education were selected as control variables [27] [33] [34].

\section{Analyses and Results}

\subsection{Descriptive Statistics and Correlation Analysis.}

Descriptive statistics and correlation analysis results are shown in Table 1. Male accounts for $48.3 \%$. Their mean age was $33.28(\mathrm{SD}=8.53)$, and their average

Table 1. Variable descriptive statistics and relevant analysis results $(N=205)$.

\begin{tabular}{|c|c|c|c|c|c|c|c|c|c|c|c|}
\hline Variables & $M$ & $S D$ & 1 & 2 & 3 & 4 & 5 & 6 & 7 & 8 & 9 \\
\hline 1) Gender & 0.52 & 0.50 & - & & & & & & & & \\
\hline 2) Age & 33.28 & 8.53 & $-0.18^{\star}$ & - & & & & & & & \\
\hline 3) Position & 1.98 & 0.89 & -0.13 & $0.16^{*}$ & - & & & & & & \\
\hline 4) Tenur & 9.70 & 8.10 & $-0.17^{\star}$ & $0.89^{* * *}$ & 0.10 & - & & & & & \\
\hline 5) Education & 15.42 & 2.16 & 0.03 & -0.07 & $0.15^{\star}$ & -0.11 & - & & & & \\
\hline 6) $P O Q$ & 3.23 & 0.49 & -0.13 & 0.11 & -0.06 & 0.12 & -0.07 & - & & & \\
\hline 7) WT & 5.21 & 1.05 & 0.02 & -0.04 & $0.28^{* * *}$ & -0.05 & 0.11 & $-0.26^{* * *}$ & - & & \\
\hline 8) FWSS & 3.01 & 0.99 & -0.06 & -0.03 & 0.08 & 0.02 & -0.08 & $0.31^{\star \star \star}$ & $0.30^{* * *}$ & - & \\
\hline 9) $\mathrm{WE}$ & 4.97 & 1.27 & 0.06 & -0.02 & $0.30^{\star * *}$ & -0.06 & 0.10 & $-0.27^{\star * *}$ & $0.49^{* * *}$ & 0.02 & - \\
\hline
\end{tabular}

Note: $\mathrm{N}=195 ;{ }^{*} p<0.05 ;{ }^{* *} p<0.01 ;{ }^{* * *} p<0.001$. $\mathrm{POQ}=$ perceived overqualification; WT $=$ thriving at work; FWSS = future work self salience; WE = work engagement. Gender: 1 = male, $0=$ female, Education: 6 = Primary school, $9=$ Junior high school, $12=$ Senior high school, $15=$ Junior college, $16=$ Undergraduate, $19=$ Graduate, and $22=$ Doctor. Position: 1 = Ordinary employees, $2=$ primary-level managers, $3=$ Middle-level managers, $4=$ Senior-level managers. 
duration of education was $15.42(\mathrm{SD}=2.16)$. The average tenure was 9.70 years $(\mathrm{SD}=8.10)$. And, $37.1 \%$ are ordinary employees, $32.2 \%$ are primary level managers, $26.8 \%$ are middle level managers, and 3.9\% are senior level managers. POQ is significantly negatively correlated with thriving at work $(\mathrm{r}=-0.26, P<$ $0.01)$ and work engagement $(\mathrm{r}=-0.27, P<0.01)$, while thriving at work and work engagement are significantly positively correlated $(\mathrm{r}=0.49, P<0.01)$.

\subsection{Confirmatory Factor Analysis and Common Method Biases Test}

Through confirmatory factor analysis, this study examined the discriminant validity of perceived overqualification, work engagement, thriving at work and future work self salience. The results are shown in Table 2, where the four-factor model has the best fitting degree, RMSEA $<0.08$, CFI $>0.90$ and NNFI $>0.90$, so the above variables have good discriminant validity and represent four different constructs.

The homologous variance was tested by Harman single factor method [35], and the results showed that, without rotational precipitation, the variation explained by the first factor was $19.98 \%$, which was less than half of the total variance $(70.23 \%)$. Therefore, the common method biases will not cause serious impact in this study.

\subsection{Hypothesis Test}

Hierarchical regression was used to test the hypothesis in the study. The results are shown in Table 3 , the model 3 shows that POQ significantly negatively predicted individual's work engagement $(\beta=-0.63, p<0.001)$, and the results support hypothesis 1 . The model 1 shows that POQ significantly negatively predicted thriving at work $(\beta=-0.50, p<0.001)$. Moreover, the model 4 shows that thriving at work significantly positively predicted individual's work engagement $(\beta=0.48, p<0.001)$, and the negative effect of POQ on work engagement is still significant $(\beta=-0.39, p<0.05)$. Therefore, thriving at work partially mediates the relationship between POQ and work engagement.

According to the method of Hayes (2013) [36], the sample number of bootstrap is 5000 , and the test results (mediating effect $=-0.30$, bias correction CI $95 \%=[-0.58,-0.11])$ support hypothesis 2 .

Table 2. Confirmatory factor analysis results $(\mathrm{N}=205)$.

\begin{tabular}{|c|c|c|c|c|c|c|c|}
\hline Model & $\chi^{2}$ & $d f$ & $\chi^{2} / d f$ & RMSEA & CFI & NNFI & SRMR \\
\hline 1) Four-factor model: POQ; WE; WT; FWSS; & 88.66 & 48 & 1.85 & 0.06 & 0.98 & 0.97 & 0.04 \\
\hline 2) Three -factor model: POQ; WT + WE; FWSS; & 282.09 & 51 & 5.53 & 0.15 & 0.87 & 0.83 & 0.11 \\
\hline 3) Two-factor model: POQ + FWSS; WE + WT; & 355.38 & 53 & 6.71 & 0.17 & 0.83 & 0.79 & 0.14 \\
\hline
\end{tabular}

Note: $\mathrm{POQ}=$ perceived overqualification; $\mathrm{WT}=$ thriving at work; FWSS = future work self salience; WE = work engagement. 
Table 3. Hierarchical regression results.

\begin{tabular}{|c|c|c|c|c|}
\hline \multirow{2}{*}{ Variables } & \multicolumn{2}{|c|}{ WT } & \multicolumn{2}{|c|}{ WE } \\
\hline & M1 & M2 & M3 & M4 \\
\hline Intercept & $6.07^{* * *}$ & $4.18^{\star * \star}$ & $5.72^{\star * *}$ & $2.80^{\star *}$ \\
\hline \multicolumn{5}{|l|}{ Control Variables } \\
\hline Gender & 0.02 & 0.00 & 0.14 & 0.13 \\
\hline Age & -0.01 & -0.00 & 0.01 & 0.01 \\
\hline Position & $0.31^{\star * \star}$ & $0.23^{* *}$ & $0.42^{* * *}$ & $0.27^{\star *}$ \\
\hline Tenure & 0.00 & 0.00 & -0.02 & -0.02 \\
\hline Education & 0.02 & 0.04 & 0.02 & 0.01 \\
\hline \multicolumn{5}{|c|}{ Independent Variable } \\
\hline POQ & $-0.50^{* * *}$ & $-0.52^{\star * *}$ & $-0.63^{\star * *}$ & $-0.39^{*}$ \\
\hline \multicolumn{5}{|c|}{ Mediating Variables } \\
\hline WT & & & & $0.48^{\star * *}$ \\
\hline \multicolumn{5}{|c|}{ Moderating variable } \\
\hline FWSS & & $0.32^{\star * *}$ & & \\
\hline \multicolumn{5}{|l|}{ Interaction effect } \\
\hline POQ $\times$ FWSS & & $0.59^{* * *}$ & & \\
\hline$R^{2}$ & 0.14 & 0.35 & 0.16 & 0.30 \\
\hline$\Delta R^{2}$ & - & 0.21 & - & 0.14 \\
\hline$F$ & $5.36^{* * *}$ & $32.44^{* * *}$ & $6.49^{* * *}$ & $38.18^{* * *}$ \\
\hline
\end{tabular}

Note: The regression coefficients in the table are non-standardized. $\mathrm{N}=195 ;{ }^{*} p<0.05 ;{ }^{* *} p<0.01 ;{ }^{* *} p<$ 0.001. POQ = perceived overqualification; WT $=$ thriving at work; FWSS $=$ future work self salience; WE = work engagement. Gender: 1 = male, 0 = female, Education: 6 = Primary school, $9=$ Junior high school, 12 $=$ Senior high school, $15=$ Junior college, $16=$ Undergraduate, $19=$ Graduate, and $22=$ Doctor. Position: 1 = Ordinary employees, 2 = primary-level managers, 3 = Middle-level managers, $4=$ Senior-level managers.

The model 2 in Table 3 shows that the interaction between POQ and future work self salience significantly positively predicted thriving at work $(\beta=0.59, p$ $<0.001)$. Figure 2 shows the interaction between POQ and future work self salience affecting thriving at work. The simple slope analysis results show that when the level of future work self salience is high, POQ has no significant impact on thriving at work $(\beta=0.06, n s)$. And when the level of future work self salience is low, POQ has significantly negative impact on thriving at work $(\beta=$ $-1.10, p<0.001)$. Therefore, hypothesis 3 is supported.

The moderated mediating effect was tested according to the method of Hayes (2013) [36]. Results as shown in Table 4, when the level of future work self salience is low and medium, the mediating effect of thriving at work is significant, when the level of future work self salience is high, the mediating effect is not significant, and the mediating effect decreases with the improvement of future work self-definition $(-0.64,-0.30,0.03)$. The results show that the mediating effect of thriving at work in the relationship between POQ and work engagement is moderated by future work self salience, and the mediating effect becomes weaker with the improvement of future work self salience. Therefore, hypothesis 4 is supported. 


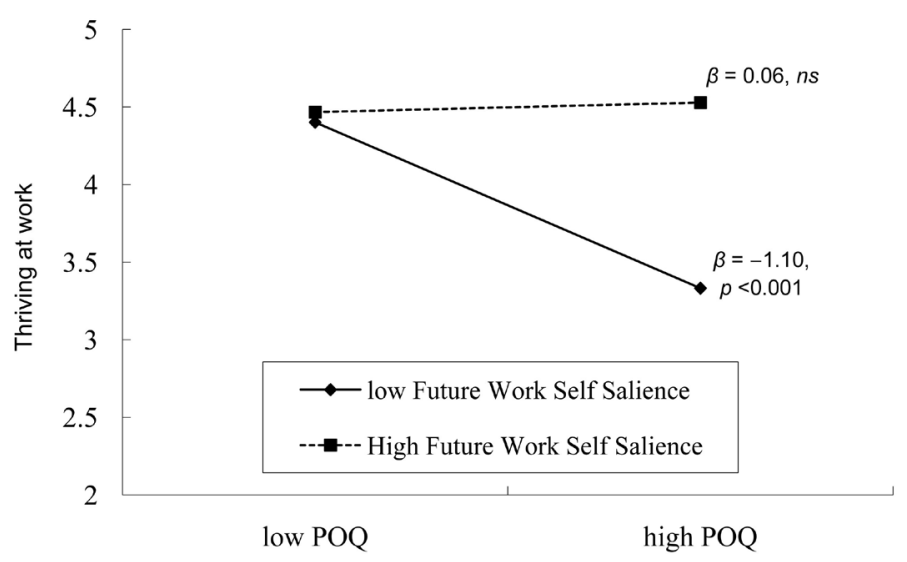

Figure 2. Moderating effect diagram of future work self salience.

Table 4. Moderated mediating effect test results.

\begin{tabular}{cccccc}
\hline & Future work self salience & Effect size & $\beta$ & Lower CI & Upper CI \\
\hline \multirow{3}{*}{ Thriving at work } & Low (-1SD) & -0.64 & 0.16 & -0.99 & -0.37 \\
& Medium (M) & -0.30 & 0.12 & -0.56 & -0.10 \\
& High (+1SD) & 0.03 & 0.19 & -0.38 & 0.39 \\
\hline
\end{tabular}

Note: If the upper and lower CI do not include 0 , the effect is significant, and vice versa; $\mathrm{CI}=95 \% \mathrm{bi}$ as-corrected bootstrapped confidence intervals.

\section{Discussion}

\subsection{Theoretical Significance}

Firstly, previous studies generally studied POQ based on relative deprivation theory, equity theory or resource conservation theory [1] [2] [5], and mostly from the perspective of organizational context. Based on SDT, this study focuses on the basic psychological needs, autonomy and internal motivation of individuals, and studies the influence of POQ on work engagement from the perspective of individual motivation, enriching the theoretical perspective and consequences research of POQ.

Secondly, both environmental factors and individual factors will affect work engagement [37]. However, few previous studies have explored the impact of the interaction between environmental factors and individual factors on work engagement. Based on SDT, this study combines the external environment that causes the POQ with the basic psychological needs and internal motivation of individuals, and explores the impact of POQ on work engagement, providing a new idea for the antecedents of work engagement.

Thirdly, studies have explored the impact of performance feedback, decision-making discretion, climate of trust/respect, and broad information sharing on thriving at work [9] [10]. And explore the relationship between thriving at work and organizational citizenship behavior, organizational loyalty and job satisfaction [11]. Starting from the phenomenon of "being overqualified" in the workplace, this study found that employees with high level of POQ lack basic 
psychological needs and the level of thriving at work is low, which affects the individual's work engagement. Therefore this study expands the research on antecedent and consequence variables of thriving at work.

Finally, most previous studies have explored the moderating model of the influence of POQ on employees' work results from the perspective of organizational context [13]. Based on SDT and from the perspective of individual, this study explores the influence of future work self salience on the relationship between POQ and thriving at work, the boundary conditions are enriched.

\subsection{Practical Significance}

Besides theoretical significance, this study also has strong practical significance.

Firstly, enterprises or organizations should make a reasonable match between employees and positions in the recruitment and allocation process, so as to enhance the sense of identity of new employees to their posts and keep them in a positive working condition.

Secondly, the organizations should pay more attention to the psychological state of employees. Through the Employee Assistance Plan (EAP) and reasonable incentive mechanism, the work enthusiasm and internal motivation can be improved, so that employees can keep vitality and learning.

Thirdly, the organizations could regularly provide employees with career development training, set up reasonable promotion mechanism, and help employees identify the future career development direction and goal, so that employees will see the hope and work hard.

\subsection{Deficiencies and Prospects}

There are still some limitations and deficiencies in this study. Firstly, this study only explored POQ from the subjective level. Future research can further explore the difference between the subjective and objective overqualifications on the impact of work engagement. Secondly, as for the boundary conditions of the influence of POQ on thriving at work, future work self salience belongs to the moderator from the perspective of cognition, so future research can start from the perspective of individual ability, for example, explore the influence mechanism of career adaptability. Finally, due to limited resources, the samples are mainly from Guangzhou. In future studies, the sample sources and scope can be expanded to improve the external validity of the research results.

\subsection{Conclusion}

Based on the self-determination theory, this study tries to examine the effect of perceived overqualification on work engagement and the associated underlying mechanism. Three conclusions can be drawn from this study: 1) POQ was negatively related to work engagement; 2) The relationship between POQ and work engagement was partially mediated by thriving at work; 3) Future work self salience moderated the relationship between POQ and thriving at work, such that this relationship was not significant when future work self salience was high. 


\section{Conflicts of Interest}

The authors declare no conflicts of interest regarding the publication of this paper.

\section{References}

[1] Vaisey, S. (2006) Education and Its Discontents: Overqualification in America, 1972-2002. Social Forces, 85, 835-864. https://doi.org/10.1353/sof.2007.0028

[2] Fine, S. (2007) Overqualification and Selection in Leadership Training. Journal of Leadership \& Organizational Studies, 14, 35-41. https://doi.org/10.1177/1071791907304291

[3] Maltarich, M.A., Reilly, G. and Nyberg, A.J. (2011) Objective and Subjective Overqualification: Distinctions, Relationships, and a Place for Each in the Literature. Industrial \& Organizational Psychology, 4, 236-239. https://doi.org/10.1111/j.1754-9434.2011.01332.x

[4] Maynard, D.C., Joseph, T.A. and Maynard, A.M. (2006) Underemployment, Job Attitudes, and Turnover Intentions. Journal of Organizational Behavior, 27, 509-536. https://doi.org/10.1002/job.389

[5] Feldman, D.C., Leana, C.R. and Bolino, M.C. (2002) Underemployment and Relative Deprivation among Re-Employed Executives. Journal of Occupational \& Organizational Psychology, 75, 453-471. https://doi.org/10.1348/096317902321119682

[6] Schaufeli, W.B., Bakker, A.B. and Salanova, M. (2006) The Measurement of Work Engagement with a Short Questionnaire a Cross-National Study. Educational \& Psychological Measurement, 66, 701-716. https://doi.org/10.1177/0013164405282471

[7] Kahn, W.A. (1990) Psychological Conditions of Personal Engagement and Disengagement at Work. Academy of Management Journal, 33, 692-724. https://doi.org/10.5465/256287

[8] Ryan, R.M. and Deci, E.L. (2000) Self-Determination Theory and the Facilitation of Intrinsic Motivation, Social Development, and Well-Being. American Psychologist, 55, 68-78. https://doi.org/10.1037/0003-066X.55.1.68

[9] Spreitzer, G., Sutcliffe, K., Dutton, J., Sonenshein, S. and Grant, A.M. (2005) A Socially Embedded Model of Thriving at Work. Organization Science, 16, 537-549. https://doi.org/10.1287/orsc.1050.0153

[10] Porath, C., Spreitzer, G., Gibson, C. and Garnett, F.G. (2012) Thriving at Work: Toward Its Measurement, Construct Validation, and Theoretical Refinement. Journal of Organizational Behavior, 33, 250-275. https://doi.org/10.1002/job.756

[11] Spreitzer, G., Porath, C.L. and Gibson, C.B. (2012) Toward Human Sustainability: How to Enable More Thriving at Work. Organizational Dynamics, 41, 155-162. https://doi.org/10.1016/j.orgdyn.2012.01.009

[12] Deci, E.L. and Ryan, R.M. (1985) Intrinsic Motivation and Self-Determination in Human Behavior. Plenum, New York. https://doi.org/10.1007/978-1-4899-2271-7

[13] Erdogan, B. and Bauer, T.N. (2009) Perceived Overqualification and Its Outcomes: the Moderating Role of Empowerment. Journal of Applied Physiology, 94, 557-565. https://doi.org/10.1037/a0013528

[14] Guan, Y., Guo, Y., Bond, M.H., Cai, Z., Zhou, X., Xu, J., et al. (2014) New Job Market Entrants' Future Work Self, Career Adaptability and Job Search Outcomes: Examining Mediating and Moderating Models. Journal of Vocational Behavior, 85, 
136-145. https://doi.org/10.1016/j.jvb.2014.05.003

[15] Strauss, K., Griffin, M.A. and Parker, S.K. (2011) Future Work Selves: How Salient Hoped-For Identities Motivate Proactive Career Behaviors. Journal of Applied Psychology, 97, 580-598. https://doi.org/10.1037/a0026423

[16] Legault, L. (2013) Self-Determination Theory. International Encyclopedia of the Social \& Behavioral Sciences, 91, 486-491.

[17] Deci, E.L. and Ryan, R.M. (2015) Self-Determination Theory. International Encyclopedia of the Social \& Behavioral Sciences, 91, 486-491. https://doi.org/10.1016/B978-0-08-097086-8.26036-4

[18] Gagné, M. and Deci, E.L. (2005) Self-Determination Theory and Work Motivation. Journal of Organizational Behavior, 26, 331-362. https://doi.org/10.1002/job.322

[19] Zhang, M.J., Law, K.S. and Lin, B. (2016) You Think You Are Big Fish in a Small Pond? Perceived Overqualification, Goal Orientations, and Proactivity at Work. Journal of Organizational Behavior, 37, 61-84. https://doi.org/10.1002/job.2024

[20] Wu, C., Tian, A.W., Luksyte, A. and Spitzmueller, C. (2017) On the Association between Perceived Overqualification and Adaptive Behavior. Social Science Electronic Publishing, 46, 339-354. https://doi.org/10.1108/PR-05-2015-0134

[21] Liu, S., Luksyte, A., Zhou, L., Shi, J. and Wang, M. (2015) Overqualification and Counterproductive Work Behaviors: Examining a Moderated Mediation Model. Journal of Organizational Behavior, 36, 250-271. https://doi.org/10.1002/job.1979

[22] Deci, E.L., Ryan, R.M., Gagne, M., Leone, D.R., Usunov, J. and Kornazheva, B.P. (2016) Need Satisfaction, Motivation, and Well-Being in the Work Organizations of a Former Eastern Bloc Country: A Cross-Cultural Study of Self-Determination. Personality \& Social Psychology Bulletin, 27, 930-942.

https://doi.org/10.1177/0146167201278002

[23] Salanova, M. and Schaufeli, W.B. (2008) A Cross-National Study of Work Engagement as a Mediator between Job Resources and Proactive Behaviour. International Journal of Human Resource Management, 19, 116-131. https://doi.org/10.1080/09585190701763982

[24] Weng, Q., Yang, H. and Cao, X. (2017) Relationship of Researcher's Career Growth and Work Engagement with Job Performance. Science Research Management, 38, 144-151.

[25] Spreitzer, G. and Porath, C. (2013) Self-Determination as Nutriment for Thriving: Building an Integrative Model of Human Growth at Work. In: Gagné, M., Ed., $O_{X^{-}}$ ford Handbook of Work Engagement, Motivation, and Self-Determination Theory, Oxford University Press, New York.

[26] Cui, Z. and Chen, L. (2016) Research on Influencing of New Generation Employee's Future Work Self Salience on Work Engagement. 1st International Symposium on Business Cooperation and Development, Kunming, 19-20 November 2016, 5-8. https://doi.org/10.2991/isbcd-16.2016.2

[27] Masvaure, P., Ruggunan, S. and Maharaj, A. (2014) Work Engagement, Intrinsic Motivation and Job Satisfaction among Employees of a Diamond Mining Company in Zimbabwe. Journal of Economics \& Behavioral Studies, 6, 488-499.

[28] Zhang, M., Ye, M., Peng, J. and Chen, Y. (2016) Future Work Self: Concept, Measurement and Related Research. Advances in Psychological Science, 24, 794-803. https://doi.org/10.3724/SP.J.1042.2016.00794

[29] Dukerich, J.M. (2001) Role Transitions in Organizational Life: An Identity-Based Perspective, by Blake E. Ashforth. Academy of Management Review, 26, 670-672. 
https://doi.org/10.2307/3560250

[30] Lin, W., Wang, L., Bamberger, P.A., Zhang, Q., Wang, H., Guo, W., et al. (2016) Leading Future Orientations for Current Effectiveness: The Role of Engagement and Supervisor Coaching in Linking Future Work Self Salience to Job Performance. Journal of Vocational Behavior, 92, 145-156. https://doi.org/10.1016/j.jvb.2015.12.002

[31] Guan, Y., Zhuang, M., Cai, Z., Ding, Y., Wang, Y., Huang, Z., et al. (2017) Modeling Dynamics in Career Construction: Reciprocal Relationship between Future Work Self and Career Exploration. Journal of Vocational Behavior, 101, 21-31. https://doi.org/10.1016/j.jvb.2017.04.003

[32] Fine, S. and Nevo, B. (2008) Too Smart for Their Own Good? A Study of Perceived Cognitive Overqualification in the Workforce. International Journal of Human Resource Management, 19, 346-355. https://doi.org/10.1080/09585190701799937

[33] Mauno, S., Kinnunen, U. and Ruokolainen, M. (2007) Job Demands and Resources as Antecedents of Work Engagement: A Longitudinal Study. Journal of Vocational Behavior, 70, 149-171. https://doi.org/10.1016/j.jvb.2006.09.002

[34] Rich, B.L., Lepine, J.A. and Crawford, E.R. (2010) Job Engagement: Antecedents and Effects on Job Performance. Academy of Management Journal, 53, 617-635. https://doi.org/10.5465/amj.2010.51468988

[35] Zhou, H. and Long, L. (2004) Statistical Remedies for Common Method Biases. Advances in Psychological Science, 12, 942-950.

[36] Hayes, A.F. (2013) Introduction to Mediation, Moderation, and Conditional Process Analysis: A Regression-Based Approach. Journal of Educational Measurement, 51, 335-337. https://doi.org/10.1111/jedm.12050

[37] Christian, M.S., Garza, A.S. and Slaughter, J.E. (2011) Work Engagement: A Quantitative Review and Test of Its Relations with Task and Contextual Performance. Personnel Psychology, 64, 89-136. https://doi.org/10.1111/j.1744-6570.2010.01203.x 